\title{
Bochdalek hernia in an adult patient in the disguise of hydropneumothorax - A diagnostic interrogation
}

\author{
Sahaja Kanugula ${ }^{1}$, and Rajanikanth R Vedula ${ }^{1, *}$
}

${ }^{1}$ Department of Radiodiagnosis, Great Eastern Medical School \& Hospital, Srikakulam, Andhra Pradesh, India

\begin{abstract}
Congenital diaphragmatic hernias are most common postero laterally which are called as Bochdalek hernias. They are very rare to occur in adults. Here we present a case of 50-year-old male who presented with acute respiratory distress with suspected diagnosis of hydropneumothorax which was later confirmed as left sided Bochdalek hernia. The defect was surgically repaired using a PTF mesh, after returning the contents of hernia into abdomen. This communication emphasizes the need to detect diaphragmatic hernia disguised as hydropneumothorax to avoid fatal complications.
\end{abstract}

Keywords: diaphragmatic hernia; hydropneumothorax; Bochdalek hernia

*Corresponding author: Prof. Rajanikanth R. Vedula MD, DMRD, FIMSA, FRCP (Glasgow), Apt.101, Woods, Somajiguda, Rajbhavan Road, Hyderabad-500082, India. Tel.: 9989773473. Email: vedula@gmail.com

Received 15 April 2021; Revised 20 May 2021; Accepted 1 June 2021; Published 11 June 2021

Citation: Kanugula S, Vedula RR. Bochdalek hernia in an adult patient in the disguise of hydropneumothorax - A diagnostic interrogation. J Med Sci Res. 2021; 9(3):178-183. DOI: http:// dx.doi.org/10.17727/JMSR.2021/9-26

Copyright: (C) 2021 Kanugula S et al. Published by KIMS Foundation and Research Center. This is an open-access article distributed under the terms of the Creative Commons Attribution License, which permits unrestricted use, distribution, and reproduction in any medium, provided the original author and source are credited.

\section{Introduction}

Bochdalek hernias are more common to occur postero laterally on the left side. Symptomatic Bochdalek hernia is rare in adults in particular on the right side. Though congenital, symptoms manifest late in life presenting usually with atypical chronic abdominal and respiratory symptoms. Pulmonary symptoms such as tension pneumothorax, pleuritis, foreign material aspiration and bacterial infection are closely mimicked by Bochdalek hernia. Mistaken diagnosis of other entities with Bochdalek hernias have been reported sporadically. Literature survey shows Bochdalek hernia presenting as pancreatitis, appendicitis and renal colic. Herniation of colon, stomach, small bowel etc., are associated with increased morbidity and mortality [1].

Radiographs frequently show abnormal findings above the dome of diaphragm like intrathoracic air fluid levels with displacement of mediastinum to opposite side simulating a hydropneumothorax, gas filled loops of bowel, soft tissue mass. Due 
to low sensitivity of chest radiograph it may be confused with other thoracic pathologies like air space consolidation, pericardial fat pad, lung collapse, sequestration or anterior mediastinal mass. Other differential diagnosis includes cysts of mediastinum or from lung, tumors, pleural effusion and empyema. Computed tomography (CT) is the investigation of choice for accurate diagnosis. In our case drainage of faecal matter from the intercostal tube was confounding with the misleading diagnosis of hydropneumothorax. This report presents late manifestation of Bochdalek hernia in an adult with a possible diagnosis of left hydropneumothorax on clinical examination and X-ray of chest. CT scan of chest lead to correct diagnosis and appropriate surgical correction. Review of Bochdalek hernia with a special tabulation of those occurring rarely on the right side is presented in this communication.

\section{Case report}

A 50-year-old male patient was admitted in the emergency ward with complaints of sudden onset of severe shortness of breath and left-sided chest pain. Left-sided hyper-resonance and decreased breath sounds in the upper chest were appreciated on auscultation. Dullness and absence of breath sounds were noted in the lower chest suggestive of left-sided hydropneumothorax. Chest radiograph revealed a large air fluid level in the left hemithorax. Trachea and cardiac shadow were displaced markedly to the right (Figure 1). Nasogastric tube in the stomach was seen in the abdominal cavity on left side confirming intra abdominal location of the stomach. In view of significant restlessness due to severe dyspnoea and radiographic findings, a chest tube was inserted using an underwater seal. There was no relief of symptoms. Faecal matter was seen draining through the tube. An immediate plain CT scan of chest revealed dilated bowel loops in the left hemithorax herniating through a defect in the left hemidiaphragm, confirming a Bochdalek hernia as an unusual feature in this adult patient (Figures 2\&3). An emergency laparotomy was performed through a midline incision which revealed a large posterior defect in the left hemidiaphragm through which dilated jejunal loops, splenic flexure and distal transverse colon were herniating into the left hemithorax. The colonic segments were incarcerated and gangrenous. The iatrogenic perforation of colon by the chest drainage tube was closed. Gangrenous segment of the colon were resected, obstruction relieved and end to end anastomosis was performed.
The defect in the diaphragm was closed using PTF mesh. Abdomen was closed in layers. Post operative chest AP radiograph demonstrated normal location of the left hemidiaphragm and normal left lung expansion (Figure 4). In the immediate following days, the patient developed peritonitis and sepsis and succumbed due to hemodynamic failure.

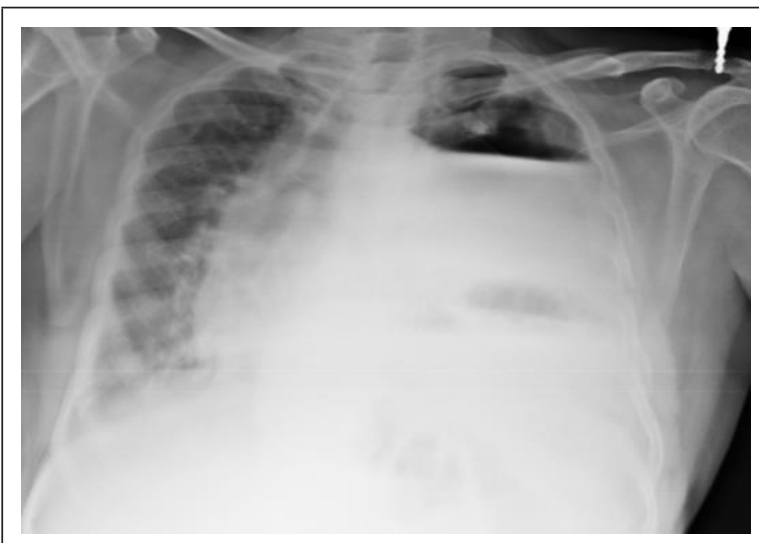

Figure 1: Chest PA view. Frontal radiograph shows air fluid levels on left side with markedly deviated trachea and mediastinum to right side.

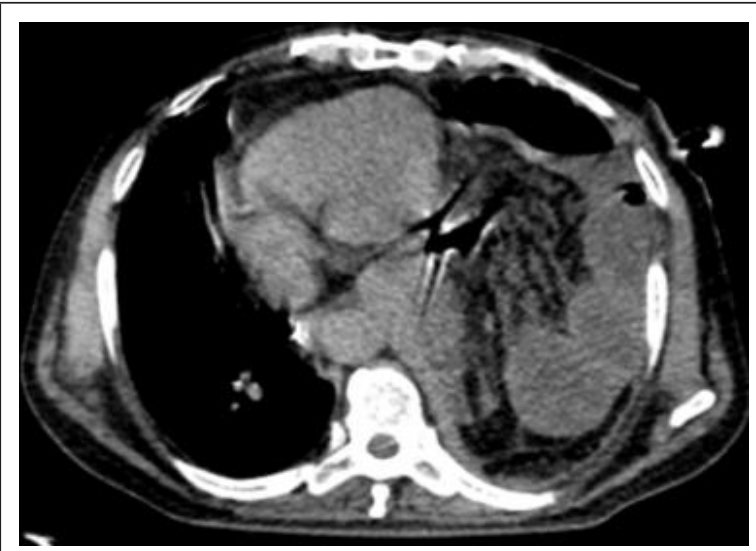

Figure 2: Non contrast axial CT scan. Dilated bowel loops are seen along with mesentery in the left hemithorax.

\section{Discussion}

Congenital diaphragmatic hernia occurs most commonly due to failure of its fusion during embryogenesis and persistence of pleuroperitoneal canal. Asymptomatic Bochdalek hernia is more common in adults with incidence ranging between one in 2000 to 7000 based on autopsy studies while symptomatic are very rare.

The incidentally diagnosed asymptomatic posterior diaphragmatic hernia in the $5^{\text {th }}$ to $7^{\text {th }}$ decades of life is reported to be $10.5 \%, 13.7 \%$, and $20.3 \%$ respectively in a prospective study of chest CT [2]. 


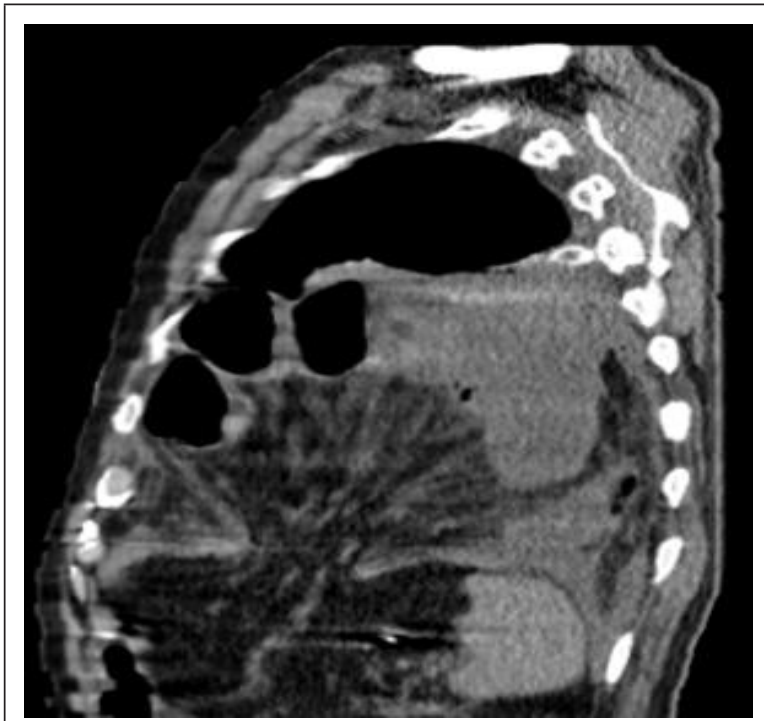

Figure 3: Non contrast CT scan. Sagittal reformation demonstrates a large defect in the left hemi diaphragm with herniated mesentery and bowel loops.

Isolated cases describing the surgical findings and outcomes of late onset hernias in adults with left sided hernias are sporadically found in the literature

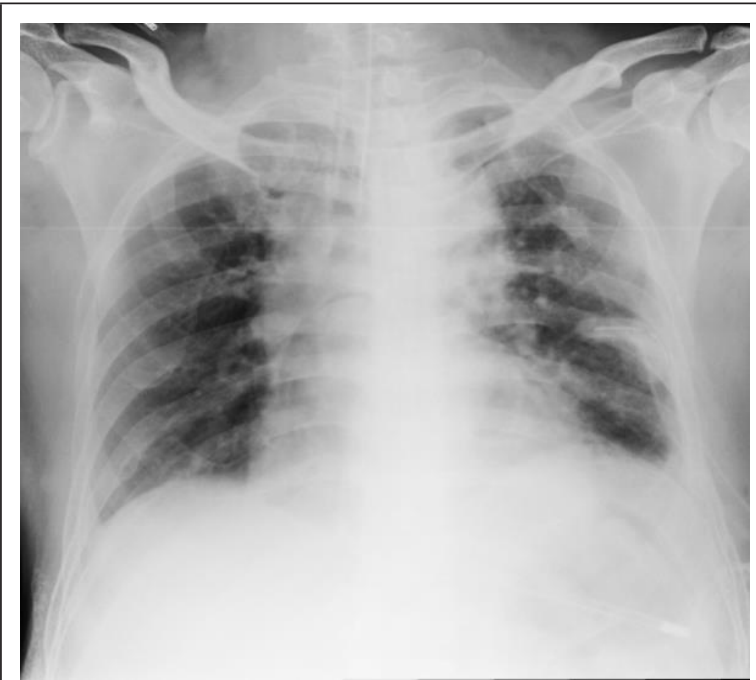

Figure 4: Chest AP view. Return of the herniated contents into abdominal cavity is demonstrated by the normally expanded left lung and normal position of the left arch of diaphragm.

[3-12]. Representative surgical cases are tabulated in Table 1.

Table 1: Review of location, contents, treatment and outcome of Bochdalek hernia (Left side).

\begin{tabular}{|c|c|c|c|c|c|c|c|}
\hline Author \& Reference no. & Age/Sex & No. & Side & Type & Content & Treatment & Outcome \\
\hline Hamid et al. [5] & $53 \mathrm{~F}$ & 1 & Left & Bochdalek & $\begin{array}{l}\text { Gastric fundal } \\
\text { diverticulum }\end{array}$ & Surgery & Good \\
\hline Bianchi et al. [3] & $\begin{array}{l}75 \mathrm{~F} \\
57 \mathrm{~F} \\
32 \mathrm{M}\end{array}$ & 3 & $\begin{array}{l}\text { Left } 2 \\
\text { Right } 1\end{array}$ & $\begin{array}{l}\text { Bochdalek } 2 \\
\text { Morgagni } 1\end{array}$ & $\begin{array}{l}\text { Colon } \\
\text { Right Kidney \& liver } \\
\text { Stomach \& Colon }\end{array}$ & $\begin{array}{l}\text { Surgery } 2 \\
\text { Refused } 1\end{array}$ & Good 2 \\
\hline Vega et al. [4] & $35 \mathrm{M}$ & 1 & Left & Bochdalek & Ascending colon \& Spleen & Nil & Nil \\
\hline Zhou et al. [6] & $50 \mathrm{M}$ & 1 & Left & Bochdalek & $\begin{array}{l}\text { Stomach } \\
\text { [Gangrene] }\end{array}$ & Surgery & Good \\
\hline Paltaci et al. [8] & $44 \mathrm{~F}$ & 1 & Left & Bochdalek & Stomach, spleen \& colon. & Surgery & Good \\
\hline Yagmur et al. [7] & $22 \mathrm{~F}$ & 1 & Left & Bochdalek & $\begin{array}{l}\text { Omentum and transverse } \\
\text { colon. }\end{array}$ & Laproscopy & Good \\
\hline Luther et al. [10] & $25 \mathrm{M}$ & 1 & Left & Bochdalek & Stomach, spleen \& colon. & Surgery & Good \\
\hline Andrade et al. [1] & $54 \mathrm{M}$ & 1 & Left & Bochdalek & Stomach & Surgery & $\begin{array}{l}\text { Death } \\
\text { due to sepsis }\end{array}$ \\
\hline Ladumor et al. [9] & $32 \mathrm{M}$ & 1 & Left & Bochdalek & Ascending colon \& Spleen & Surgery & Good \\
\hline Niwa et al. [11] & $53 \mathrm{~F}$ & 1 & Left & Bochdalek & Stomach \& Omentum & Surgery & Good \\
\hline Kocakusak et al. [12] & $21 \mathrm{M}$ & 1 & Left & Bochdalek & Colon Necrosis & Surgery & Good \\
\hline Present author & $50 \mathrm{M}$ & 1 & Left & Bochdalek & Descending Colon & Surgery & Good \\
\hline
\end{tabular}

Right sided symptomatic Bochdalek hernia is rare in adults. Effect of liver protection by liver and spleen on either side and also a thin hernial sac containing both pleura and peritoneum were proposed as reasons for 
the late onset of presentation [13]. Often Bochdalek hernia is initially misdiagnosed as pneumonia, pleural effusion or tension pneumothorax. Less common manifestations include breathlessness or chest infections, neoplastic disease, pulmonary sequestration, foreign material aspiration, tension pneumothorax, pneumonia, pleuritis or pulmonary tuberculosis. Late onset of Bochdalek's hernia presenting primarily with respiratory symptoms or strangulation of gangrenous omentum, have been reported [4-13]. The small fat-containing hernias have no clinical implication, while the large ones containing abdominal viscera are associated with increased morbidity and mortality. The cause of late presentation is due to plugging of the defect in the diaphragm by omentum and part of the bowel.
Left sided hernia is the most common type of congenital diaphragmatic hernia and it occurs through a defect in the posterolateral defect in the diaphragm. CT reveals discontinuity in the diaphragm with herniation of large and small bowel loops most commonly [14].

Intrathoracic kidney was reported occasionally associated with Bochdalek hernia mostly on the left side $[4,15]$. Interestingly, there was no right sided Bochdalek hernia in a large case series of the 40 patients operated for diaphragmatic hernia over a period of 10 years. Presenting symptoms and operative observations including outcome of right sided Bochdalek hernia are drawn from the literature (Table 2).

Table 2: Review of patient summary of right sided Bochdalek hernia (Right side).

\begin{tabular}{|c|c|c|c|c|c|c|}
\hline Author \& Reference no. & Age/Sex & $\begin{array}{l}\text { No.of } \\
\text { cases }\end{array}$ & Side & Content & Treatment & Outcome \\
\hline Kanazawa et al. [16] & $63 \mathrm{~F}$ & 1 & Right & $\begin{array}{l}\text { Strangulated colon and right } \\
\text { kidney }\end{array}$ & Surgery & Good \\
\hline Song et al. [17] & $86 \mathrm{~F}$ & 1 & Right & Dilated proximal ureter & Surgery & Good \\
\hline Almeida et al. [18] & $49 \mathrm{~F}$ & 1 & Right & Ileocecal \& appendix & Surgery & Good \\
\hline Shimizu et al. [13] & $15 \mathrm{M}$ & 1 & Right & Omentum & Conservative & NA \\
\hline Karaoglanoglu et al. [15] & $\begin{array}{c}22 \\
\text { months M }\end{array}$ & 1 & Right & $\begin{array}{l}\text { RightKidney } \\
\text { Colon }\end{array}$ & Surgery & Good \\
\hline Fan et al. [19] & & 1 & Right & Omentum and transverse colon. & Laproscopy & Good \\
\hline Patel et al. [20] & $50 \mathrm{~F}$ & 1 & Right & $\begin{array}{l}\text { Hepatic flexure,transverse colon } \\
\text { with omentum and right kidney }\end{array}$ & Surgery & Good \\
\hline Bianci et al. [3] & $57 \mathrm{~F}$ & 1 & Right & Right Kidney \& liver & Refused surgery & NA \\
\hline Elilna et al. [21] & $38 \mathrm{~F}$ & 1 & Right & Liver andhepatic flexure & Surgery & Good \\
\hline Santos-netto et al. [22] & $45 \mathrm{~F}$ & 1 & Right & $\begin{array}{l}\text { Right hepatic lobe, the right } \\
\text { kidney and right adrenal gland, } \\
\text { twisting of common bile duct }\end{array}$ & Surgery & $\begin{array}{l}\text { Death due to } \\
\text { sepsis weeks } \\
\quad \text { later }\end{array}$ \\
\hline Choi et al. [23] & $29 \mathrm{M}$ & 1 & Right & $\begin{array}{l}\text { Ascending colon, mesentery, } \\
\text { small bowel, duodenum, } \\
\text { pancreatic head } \\
\text { Hypoplastic liver }\end{array}$ & Surgery & Good \\
\hline
\end{tabular}

Rare presentations such as obstructive uropathy, ileo-cecal appendix, acute pancreatitis in an adult and acute respiratory failure and ectopic ureter have been described [18]. Plain frontal and lateral chest radiographs often demonstrate multiple air fluid levels or soft tissue opacities in the hemithorax above the diaphragm.
Eventration is considered a close differential diagnosis which also shows abdominal contents seemingly high inside the thoracic cavity because of the elevated but intact diaphragm without any discontinuity. However the defect in the diaphragm cannot be demonstrated by plain radiography. Peristaltic bowel shadows may be appreciated within 
the lungs, an observation noted in the pediatric age group [15]. On plain radiograph of chest other differential diagnosis includes cysts of mediastinum or from lung, tumors, pleural effusion and empyema. Chest radiograph is less sensitive to establish the diagnosis compared to cross sectional imaging.

The present case emphasizes the hazard of placement of a chest tube that might result in iatrogenic perforation and field contamination of thoracic and abdominal cavities communicating through the diaphragmatic defect. Technique of chest tube insertion also influences the risk of bowel perforation. Time lapse between the onset of gangrene and presentation of the patient determine the outcome despite the best surgical efforts. Poor outcome in our patient is probably due to the inadvertent peritonitis superimposed on existing gangrenous bowel.

With the use of multidetector computed tomography (MDCT) scanning of chest unsuspected diaphragmatic hernias are increasingly detected in the routine examinations with sensitivity of $78 \%$ on left side and $50 \%$ for the right side. High prevalence of $10 \%$ (171 hernias in 142 adult patients) of Bochdalek hernia was demonstrated in a study of 1350 consecutive routine MDCT scans. Posterolateral paraspinal opacity on chest radiograph was conclusively diagnosed by means of MRI in a 45-year-old healthy male presenting with acute chest pain, otherwise mimicking a pulmonary nodule. MRI is also used to predict the outcome in the prenatal period. The supero-inferior relation of the diaphragm to the liver is better demonstrated by MRI than ultrasound examination because of the similarity in the echogenicity of the tissues above and below the diaphragm. Surgery should be performed as soon as the diagnosis is confirmed to avoid complications. Decompression of the thoracic cavity and repair of the defect is performed by either laparoscopic or video assisted thoracoscopic approach. Transabdominal approach is performed if obstruction or strangulation is noted and transthoracic approach is reserved for asymptomatic patients.

\section{Take-away points}

In adults Bochdalek hernias are on the left side almost always and rarely seen on the right side. Gastrointestinal symptoms are more common in comparison with pulmonary manifestations. In a patient presenting with acute respiratory embarrassment misleading radiographic findings should be kept in mind and a careful search for bowel loops passing into the thoracic cavity avoids incorrect diagnosis. CT scan of chest is the diagnostic modality of choice with high sensitivity. Prompt diagnosis and early intervention will reduce morbidity and mortality.

\section{Acknowledgments}

The authors thank Dr. MBV. Prasad, Senior Consultant \& Surgical Gastroenterologist, Krishna Institute of Medical Sciences, Secunderabad for reviewing the manuscript with useful suggestions.

\section{Conflicts of interest}

Authors declare no conflicts of interest.

\section{References}

[1] Andrade LAM, Collazos SS, Ferretiz MDLAM, Munoz FYP, Ruiz B, et al. Bochdalek hernia with gastric necrosis in a 54year-old man, case report and review of the literature. MOJ Clin Med Case Rep. 2016; 4(2):48-50.

[2] Kinoshita F, Ishiyama M, Honda S, Matsuzako M, Oikado $\mathrm{K}$, et al. Late-presenting posterior transdiaphragmatic [Bochdalek] hernia in adults: prevalence and MDCT characteristics. J Thorac Imaging. 2009; 24(1):17-22.

[3] Bianchi E, Mancini P, Vito SD, Pompili E, Taurone S, et al. Congenital asymptomatic diaphragmatic hernias in adults: a case series. J Med Cas Rep. 2013; 7:125.

[4] Vega MT, Maldonado RH, Vega GT, Vega AT, Liévano EA, et al. Late-onset congenital diaphragmatic hernia: A case report. Int J Surg Case Rep. 2013; 4(11):952-954.

[5] Hamid KS, Rai SS, Rodriguez JA, Symptomatic Bochdalek hernia in an adult. JSLS. 2010; 14(2):279-281.

[6] Zhou Y, Du H, Che G. Giant congenital diaphragmatic hernia in an adult. J Cardiothorac Surg. 2014; 9:31.

[7] Yagmur Y, Yiğit E, Babur M, Gumuş S. Bochdalek hernia: A rare case report of adult age. Ann Med Surg [Lond]. 2015; 5:72-75

[8] Paltaci I, Temiz M, Kaplan A, Daban U, Kizilkaya E. Congenital diaphragmatic hernia in an adult presenting with ileus: A case report. J Med Case. 2014; 5(4):194-196.

[9] Ladumor S, Adham D. Non-traumatic diaphragmatic hernia in adult: Case report. J Surg. 2017; 6(2):555682.

[10] Luther A, Mahajan A. Left-sided Bochdalek hernia in an adult: A case report with review of literature. J Int Med Sci Acad. 2015; 28(1):33-34.

[11] Niwa T, Nakamura A, Kato T, Kutsuna T, Tonegawa K, et al. An adult case of Bochdalek hernia complicated with hemothorax. Respiration. 2003; 70(6):644-646.

[12] Kocakusak A, Arikan S, Senturk 0, Yucel AF. Bochdalek's hernia in an adult with colon necrosis. Hernia. 2005; 9(3):284-287

[13] Shimizu T, Hira S, Hirooka S, Yonekura T, Tamai H. Late onset of right Bochdalek's hernia with strangulation of the omentum. Acta Paediatr. 2002; 91(4):483-485. 
[14] Sodhi KS, Virmani V, Sandhu MS, Khandelwal N. Indian J Surg. 2015; 77(2):104-110.

[15] Karaoglanoglu N, Turkyilmaz A, Eroglu A, Alici HA. Rightsided Bochdalek hernia with intrathoracic kidney. Pediatr Surg Int. 2006; 22(12):1029-1031.

[16] Kanazawa A, Yoshioka Y, Inoi O, Murase J, Kinoshita H. Acute respiratory failure caused by an incarcerated right-sided adult Bochdalek hernia: Report of a case. Surgery Today. 2002; 32(9):812-815.

[17] Song YS, Hassani C, Nardi PM. Bochdalek hernia with obstructive uropathy. Urology. 2011; 77(6):1338.

[18] Almeida CEC, Reis LS, Almeida CMC. Adult right-sided Bochdalek hernia with Ileo-Cecal appendix: Almeida-Reis hernia. Int J Surg Case Rep. 2013; 4(9):778-781.

[19] Fan MJ, Coulson ML, Siu SK. Adult incarcerated right-sided Bochdalek Hernia. Aust NZJ Surg. 1999; 69(3):239-241.

[20] Patel NM, Tantia OM, Prasad P, Das PC, KhannaS. Laparoscopic repair of right sided Bochdalek hernia - A case report. Indian J Surg. 2013; 75(Suppl 1):303-304.

[21] Elilna L, Seppo S, Tapio HJ. Right-sided Bochdalek hernia in an adult: A case report. J Med Case Rep. 2009; 3:9291.

[22] Santos-Netto JMD, Oliveira CVC, Sousa MG. Right-sided Bochdalek hernia in adult associated with cholestatic syndrome: Case report. Arq Bras Cir Dig. 2015; 28(4):299302.

[23] Choi YK, Ahn JH, Kim KC, Won TH. An adult right-sided Bochdalek hernia accompanied with hepatic hypoplasia and inguinal hernia. Korean J Thorac Cardiovasc Surg. 2012; 45(5):348-350. 